\title{
Evaluation of patient satisfaction and the service quality of the outpatient care at the Heart Institute of Ho Chi Minh City
}

\author{
Dinh Hong Diem Thuy ${ }^{1}$, Tran Thi Thanh Phuong ${ }^{2 *}$, Nguyen Huu Khanh ${ }^{1}$, \\ Nguyen Truong Vien ${ }^{3}$ \\ ${ }^{1}$ Heart Institute of Ho Chi Minh City, Department of Planning and Administration, Vietnam \\ ${ }^{2}$ University of Economics Ho Chi Minh City, School of Management, Vietnam \\ ${ }^{3}$ University of Medicine and Pharmacy at Ho Chi Minh City, Vietnam \\ *Corresponding author: phuong.tran@ueh.edu.vn
}

\section{ARTICLE INFO}

DOI: $10.46223 /$ HCMCOUJS.

econ.en.11.1.1307.2021

Received: November $5^{\text {th }}, 2020$

Revised: January $21^{\text {st }}, 2021$

Accepted: February $5^{\text {th }}, 2021$

Keywords:

patient satisfaction, treatment and care, quality of healthcare, cardiology services, medical outcomes study, outpatient department, healthcare services

\section{ABSTRACT}

Background and aims: Research on patient satisfaction with the outpatient service quality at the hospitals has been undertaken in both developed countries and developing countries. However, there remains a paucity of studies evaluating patient satisfaction at the cardiovascular related services. This study assesses the levels and determinants of patient satisfaction with outpatient care at the Heart Institute of Ho Chi Minh City, Vietnam in 2018.

Methods: A cross-sectional descriptive survey was conducted at the Heart Institute of Ho Chi Minh City from June to November 2018. Patients and relatives were face to face interviewed on satisfaction questionnaires of Vietnam's Ministry of Health.

Results: Satisfaction of patients and relatives about the quality of outpatient care was high, reaching the average 87.3 percent of patients' expectation with the minimum of 50 to 100 . The booking appointments via phone/online services, long times waiting, and toilet/drinking water facilities are also the lowest level of satisfaction. "The transparency of the information", "the behavior and competence of medical staff and service staff", and "the quality of the medical infrastructure and facilities" are three dimensions that impacted patient satisfaction.

Conclusions: Overall most of the patients positively evaluated the outpatient services at the Heart Institute of Ho Chi Minh City but there are still some aspects of healthcare services that need to improve such as the booking services, the toilet and drinking facilities, the long waiting times and more transparent information.

\section{Introduction}

The patient has been regarded as consumers and patient satisfaction is one of the important factors that determine the quality of health care facilities (Gogoi \& Choudhury, 2015; Mitropoulos, Vasileiou, \& Mitropoulos, 2018; Sitzia \& Wood, 1997). Many studies have considered patient satisfaction as a quality measurement tool for healthcare providers (Bird et al., 2018; Hoang, Dao, Wall, Nguyen, \& Byass, 2006; Singh \& Kumar, 2015). In Vietnam, before 2015 due to the poor infrastructure, the public hospitals in Vietnam did not place the emphasis on patient satisfaction as 
a measure of the quality of care. Historically, hospital managers have focused on the outcome of surgeries and treatment as a measure of "patient satisfaction" but ignored the patient's perspective of quality of care.

Hospitals in Vietnam granted their self-governance in 2016. In response to the levels of increased competition, the hospital managers started to pay attention to patient's perspectives and inputs towards care quality. Since 2016, the public hospitals in Vietnam has circulated questionnaire every six months to assess patient perspectives of quality of care during their treatment with the hospitals (Nguyen \& Mai, 2014). These findings guided the top management identify areas of concern and improve the services.

Research on patient satisfaction with the outpatient service quality at the hospitals have been undertaken in both developed countries (Gogoi \& Choudhury, 2015; Kulkarni, 2018; Stefanovska \& Petkovska, 2014) and developing countries (Ho, 2015; Nguyen \& Mai, 2014; Pham, Le, Bui, \& Ly, 2011; Tran \& Nguyen, 2012). These studies examined various dimensions of healthcare services including "the medical infrastructure and the facilities", "the accessibility to healthcare services" and "the attitude and the competence of medical staff". However, there remains a paucity of studies evaluating patient satisfaction at the cardiovascular related services. Cardiovascular diseases (CVDs) have become a chronic disease that requires so much care in Vietnam. In Viet Nam, CVDs were responsible for $31 \%$ of total deaths in 2016 - equivalent to more than 170,000 (WHO, 2016). In 2016, it represented about 12 percent of all new cancer cases and 25 percent of all cancers in women (WHO, 2016). This study focuses on providing empirical evidence to evaluate the out-patient satisfaction towards the quality of cardiovascular care and treatment at the Heart Institute of Ho Chi Minh city (CMI) in Vietnam. In this study, the patient's satisfaction is assessed in terms of two objectives:

i) To assess patient satisfaction regarding the services provided in the outpatient department;

ii) To assess the patient satisfaction among different socio-demographic characteristics of patients.

\section{A literature review of patient satisfaction towards outpatient care and service quality}

Patient satisfaction is considered an important component in evaluating the quality of healthcare as well as the health care system (Sitzia \& Wood, 1997; Williams, 1994) (Kulkarni, 2018). Patient satisfaction is achieved when the patient's perception of the quality of care and services that they receive in hospitals has been positive, satisfying and meets their expectations (Singh \& Kumar, 2015).

Many previous studies have developed and applied patient satisfaction as a quality improvement tool for healthcare provides (Al-Abri \& Al-Balushi, 2014; Batchelor, Owens, Read, \& Bloor, 1994; Cronin \& Taylor, 1992; Olusina, Ohaeri, \& Olatawura, 2002; Williams, 1994). The patient satisfaction measurement serves three purposes (Kulkarni, 2018) that (a) to reflect the quality of healthcare services from the patient's perspectives, (b) to identify problem areas in healthcare organizations and generate ideas for solutions, and (c) to evaluate healthcare. In an extensive electronic search of the literature, we found that tools developed to measure patient satisfaction have generally taken one of two forms: episode-specific or general (Kulkarni, 2018). The SERVQUAL scale (Parasuraman, Zeithaml, \& Berry, 1988) has widely used to measure the quality of medical services (Bird et al., 2018). Patient assessment of hospital outpatient care 
includes various dimensions of quality of services such as tangibles, responsiveness, communication, attitude, clinical and comforting skill, amenities, food services.

The majority of studies had been conducted in India. These studies found that the highest percentages of the patients were not satisfied with the cleanliness of the hospital, the washroom facility and the waiting area. A study was undertaken to assess patient satisfaction with health care services at the outpatient department of Maharaja Aggarsain General Hospital, Hisar (Singh \& Kumar, 2015). The study randomly recruited 100 respondents irrespective of age, gender, education, income. This study found that there was a fair level of patient satisfaction about the hospital structure, hospital process and hospital performance. The overall mean responses were $2.73( \pm 0.57), 2.176( \pm 0.93)$, and $2.607( \pm 0.76)$. However, the study found that most patients were not happy with the cleanliness of the washroom facility and waiting area.

Another cross-sectional study of patient satisfaction was carried out in an outpatient department of a tertiary care hospital in Maharashtra (Kulkarni, 2018) during December 2017. A 100 randomly patients of all ages were selected, a majority of patients belonged to the age group $15-45$ years with a mean age of $42.9( \pm 19.53)$. The study found that the overall satisfaction level was $73 \%$ excellent to good, $22 \%$ average. $68 \%$ of respondents were unsatisfied with the toilet facility and $56 \%$ were unsatisfied with the drinking water facility and 50\% were not satisfied regarding convenience to reach pharmacists. The most frequent explanation for the variation and low-quality care in the developing world was the lack of resources (Olusina et al., 2002) (Sachdeva \& Kaur, 2018).

According to our search, there is only one study from Australia evaluating patient satisfaction with cardiology quality care (Stefanovska \& Petkovska, 2014). The study used a specially developed "Medical Outcomes Study, Patient Satisfaction Questionnaire" (MOS PSQIII) and found that patients positively evaluated financial accessibility and quality of health services, even though some aspects of health care needed improvement such as the accessibility of healthcare services. This study also found that gender, age and education were the socioeconomic determinants of satisfaction with healthcare quality. Study contexts in Australia and Vietnam have many differences in service needs, expectations, socio-cultural characteristics and languages, and MOS PSQ-III is an unpopular questionnaire in Vietnam. These can create barriers to apply similar studies in Vietnam. Using a popular questionnaire help increase the comparability and applicability of study results in Vietnam.

In 2005, the Ministry of Health (MOH) in Vietnam initiated the development of a patient satisfaction survey for outpatient and inpatients based on specific criteria within the five dimensions of service quality: 1) Accessibility 2) Transparency 3) Quality of infrastructure 4) Behaviour and competence of staff, and 5) Outcome of service delivery. The scale consists of 32 items across these five dimensions, and each item is used to measure the customer expectation and the customer perception of the service provided. The surveys have been standardized and validated and can be used in the health-care setting as quality-improvement tools.

The outpatient department at Heart Institute of Ho Chi Minh City (CMI) has received 300,357 check-ups in 2018 according to the annual report of the Institute. The Heart Institute is well-known for its band of doctors and professionals in treating patients with cardiovascular diseases. However, the effectiveness of the health system depends upon many factors not only having professional doctors. The CMI has circulated the $\mathrm{MOH}$ survey to evaluate patient satisfaction towards health service quality annually since 2016. 


\section{Research methodology}

\subsection{The setting}

The Heart Institute of Ho Chi Minh City was founded in early 1992 by Professor Alain Carpentier, a well-known French cardiac surgeon and late Professor Duong Quang Trung who was at the time director of the Department of Health of Ho Chi Minh City. This is a non-profit organization and is the cooperation of Viet-French relations. The Institute laid the foundation for developing cardiac surgery and treating advanced cardiovascular pathologies for the country. According to the annual report, the CMI has implemented cardiac surgery for more than 32.748 patients with congenital heart disease. Coronary angioplasty and treatment of congenital heart disease by cardiac catheterization was for more than 32,500 patients, examination and treatment of 3 million cardiovascular patients.

\subsection{Study design, sampling and data collection}

A cross-sectional study was conducted at the CMI among patients attending the outpatient department (OPD) during the period from 1/1/2018 to 30/12/18. Our sample comprised 401 new patients with cardiovascular diseases for all ages attending the outpatient department. A simple random sampling technique was used to select patients attending different specialty departments of the Institute. The respondents were interviewed at the exit point of the outpatient department after taking informed consent. Patients not willing to participate and follow-up patients were excluded from the study. The patients and accompanying persons either parents or relatives for pediatric age less than 15 years were interviewed at the exit point of the hospital after taking informed consent. The data were collected based on the Ministry of Health (MOH) questionnaire and without interference from staff. The ethical committee at the CMI approved the methodology and data collection procedure of the study. The patients were told that the purpose of the study was to assess the patient satisfaction of services provided by the hospital so as to bring further improvement in services. The patients were also told that the investigator was not part of the treatment team and they were free to give their responses. The patient's respondents were then submitted to the MOH online portal.

\subsection{Instruments of collecting data for service quality and patient satisfaction}

This study employed the scales designed by MOH to suit reality to measure the quality of medical examination and treatment services in Vietnam. The questionnaire used in our study consists of two main parts of which the first part is about personal information of the patient, and the second part includes questions about the patient's evaluation of healthcare service quality, his/her satisfaction with the healthcare services and the intention of coming back to the Institute. or introducing the treatment to others.

The MOH scale is a self-report questionnaire that consists of 32 statements which cover the experiences of patients in the outpatient department the following five domains (see Table 3): Accessibility to services (first five items of Table 3), Transparency of information (10 items), Medical infrastructure and facilities ( 8 items), Competence of medical and non-medical staff (4 items) and Outcome of service delivery (4 items). The validity and reliability of the questionnaires were determined by the Ministry of Health in Vietnam.

Patient satisfaction was classified according to Likert scale, with 5 levels: Level I: Very unhappy, very bad, very disagree. Level II: Not satisfied, not good, disagree. Level III: Acceptable. Level IV: Satisfied, good, agree. Level V: Very satisfied, very good, very agree. There is the question for a patient to rate from 1 to 5 to whether "I would definitely return to the Institute 
again". The patients choose whether they would like to come back or introduce services to others. The patients were also told that the investigator was not part of the treatment team and they were free to give their responses.

In addition, this study employed a one-item scale ranging from 0 to 100 measuring overall patient satisfaction score with the quality of healthcare services at the Institute. The respondents were asked to indicate their level of agreement with the statement "Overall I am satisfied with the quality of healthcare services in the hospital". Although a multiple-item measure like a 5-point Likert scale would often be desirable, the literature has suggested that employing single-item measures of global satisfaction (Olusina et al., 2002).

\subsection{Data analysis}

The proportion of respondents answering each item was recorded. The total score for each domain and overall $\mathrm{MOH}$ scale was obtained by taking averaging the scores of the constituent items.

In order to test the proposed hypotheses, we ran multiple linear regression analyses using the overall patient satisfaction score and the patient satisfaction for the outcome of service delivery as two dependent variables. The independent variables were the four dimensions of service quality (i.e., accessibility to healthcare services, transparency of information, the competence of healthcare staff, the medical infrastructure and facilities and the outcome of health service delivery).

Multivariable logistic regression (Sitzia \& Wood, 1997) was employed to test the differences of dissatisfaction proportion between each patient's characteristics group. Dissatisfaction in this study was defined as the total score for the overall MOH scale lower than 4. All of our hypothesis tests were acceptable at type I error proportion less than 0.05 .

\section{Results}

\subsection{Characteristics of patients}

The results presented in Table 1 are for 401 completers. Out of 401 respondents, there were 155 males $(38.7 \%)$ and 246 females $(61.3 \%)$. A majority of patients belonged to the age group 18-59 years with a mean age of 51.85 \pm 22.3 . The sample covered a wide range of ages from $15-$ 92 years. $91.8 \%$ of respondents were patients themselves and $8.2 \%$ of respondents were accompanying persons either parents or relatives for pediatric age less than 15 years of age. Nearly half of patients held health insurance (45.6\%). About more than half of patients $(65.6 \%)$ live less than $200 \mathrm{~km}$ from home to the Institute.

\section{Table 1}

The socio-demographic characteristics of patients $(\mathrm{N}=401)$

\begin{tabular}{|c|c|c|}
\hline Socio-demographic variable & Frequency & $\%$ \\
\hline \multicolumn{3}{|l|}{ Response types: } \\
\hline Patients & 365 & 91.8 \\
\hline Relatives & 36 & 8.2 \\
\hline \multicolumn{3}{|l|}{ Gender: } \\
\hline Male & 155 & 38.7 \\
\hline Female & 246 & 61.3 \\
\hline Age range (years) & $\begin{array}{l}\text { Mean (SD): } \\
51.85 \pm 14.9\end{array}$ & Range: $15-92$ \\
\hline$<18$ & 8 & 2.0 \\
\hline
\end{tabular}




\begin{tabular}{|c|c|c|}
\hline Socio-demographic variable & Frequency & \% \\
\hline $18-59$ & 214 & 53.4 \\
\hline$\geq 60$ & 179 & 44.6 \\
\hline Insurance: & & 45.6 \\
\hline Yes & 183 & 54.4 \\
\hline No & 218 & \\
\hline Distance from home to the Institute: & & 65.6 \\
\hline$<200$ & 263 & 34.1 \\
\hline$\geq 200$ & 138 & \\
\hline
\end{tabular}

Source: The researcher's data analysis

\subsection{Patients' satisfaction with service quality}

Satisfaction was adequate for all the domains of healthcare services relating to the accessibility of healthcare services, transparency of information, the quality of facilities, the competence of medical staff, and the outcome of service delivery. The distribution of patient respondents was similar across five domains. More than half of the patient's responses were attributable to the score of 4 or 5 indicating that patient was satisfied or extremely satisfied with the services.

Regarding the accessibility of healthcare services, Table 2 indicates that the respondents were satisfied with the clear diagrams, signs showing directions to the departments and rooms in the hospital, clear blocks and stairs to find, and the flat pathways to move around. The patients were well-informed about the time to visit. However, about $30 \%$ of respondents were not satisfied with booking services via phone, and website as the CMI has not presently implemented the booking via online services.

\section{Table 2}

Distribution of responses from the respondents according to the accessibility of healthcare services $(n=401)(\%)$

\begin{tabular}{|l|c|c|c|c|c|c|}
\hline \multicolumn{1}{|c|}{ Items of care } & \multicolumn{5}{|c|}{ Frequency (\%) } & Mean \pm SD \\
\cline { 2 - 7 } & $\mathbf{1}$ & $\mathbf{2}$ & $\mathbf{3}$ & $\mathbf{4}$ & $\mathbf{5}$ & \\
\hline $\begin{array}{l}\text { 1. Diagrams, signs showing directions to the } \\
\text { departments and rooms in the hospital are clear } \\
\text { and easy to understand and easy to find }\end{array}$ & 0.3 & 2.0 & 8.7 & 57.1 & 31.9 & $4.18 \pm 0.69$ \\
\hline 2. Time to visit patients is clearly informed & 0.3 & 1.0 & 10.7 & 55.3 & 32.7 & $4.19 \pm 0.68$ \\
\hline $\begin{array}{l}\text { 3. Blocks, stairs and rooms are clearly numbered } \\
\text { and easy to find }\end{array}$ & 0.3 & 1.2 & 13.4 & 52.4 & 32.7 & $4.16 \pm 0.71$ \\
\hline $\begin{array}{l}\text { 4. The pathways in the hospital are flat and easy to } \\
\text { move around }\end{array}$ & 0.3 & 0.7 & 13.9 & 52.4 & 32.7 & $4.16 \pm 0.70$ \\
\hline $\begin{array}{l}\text { 5. Customers can find out information and register } \\
\text { for examination by phone, the website of the } \\
\text { hospital conveniently }\end{array}$ & 0.3 & 1.7 & 25.7 & 51.1 & 21.2 & $3.91 \pm 0.74$ \\
\hline Accessibility of healthcare services (Average) & & & & & & $\mathbf{4 . 1 2} \pm \mathbf{0 . 5 8}$ \\
\hline
\end{tabular}

Note: 5=Strongly Agree, 4=Agree, 3=Neither Agree nor Disagree, 2=Disagree, 1=Strongly Disagree Source: Primary data 
Regarding the transparency of information and procedures for medical examination and treatment, Table 3 shows that most of the respondents were satisfied with the well-informed processing of consultation, the clear quoted price of consultation, the welcomed spirit of the staff. However, with a regard to the waiting times, about $35 \%$ of patients were not happy with the waiting time for the registration, to see the doctors, to get the investigation check from OPD and time taken in getting the results from investigations. One explanation for the long waiting times was the lack of doctors speciliased in heart problems against the number of patients visiting the Institute.

\section{Table 3}

Distribution of responses from the respondents according to the transparency of information and procedures for medical examination and treatment $(n=401)(\%)$

\begin{tabular}{|c|c|c|c|c|c|c|}
\hline \multirow[t]{2}{*}{ Items of care } & \multicolumn{5}{|c|}{ Frequency $(\%)$} & \multirow[t]{2}{*}{ Mean \pm SD } \\
\hline & 1 & 2 & 3 & 4 & 5 & \\
\hline $\begin{array}{l}\text { 6. The medical examination process is clearly and } \\
\text { publicly available and easy to understand }\end{array}$ & 0.5 & 1.0 & 8.5 & 49.9 & 40.1 & $4.28 \pm 0.70$ \\
\hline $\begin{array}{l}\text { 7. The procedures and procedures for the medical } \\
\text { examination have been reformed to be simple and } \\
\text { conveniently }\end{array}$ & 0.5 & 1.0 & 15.9 & 48.9 & 34.7 & $4.15 \pm 0.75$ \\
\hline $\begin{array}{l}\text { 8. Prices of medical services are clearly and } \\
\text { publicly listed }\end{array}$ & 0.3 & 0.3 & 10.2 & 51.8 & 37.4 & $4.26 \pm 0.67$ \\
\hline $\begin{array}{l}\text { 9. Medical staffs welcome and guide patients to } \\
\text { make affable procedures }\end{array}$ & 0.5 & 0.7 & 13.0 & 56.4 & 29.4 & $4.13 \pm 0.69$ \\
\hline $\begin{array}{l}\text { 10. Assess the lining up in the order first after the } \\
\text { procedures for registration, payment, examination, } \\
\text { testing, screening }\end{array}$ & 0.5 & 1.2 & 17.0 & 52.6 & 28.7 & $4.08 \pm 0.74$ \\
\hline $\begin{array}{l}\text { 11. Assess the waiting time for registration } \\
\text { procedures }\end{array}$ & 0.5 & 5.0 & 29.7 & 41.9 & 22.9 & $3.82 \pm 0.86$ \\
\hline $\begin{array}{l}\text { 12. Assess the waiting time for the doctor's turn to } \\
\text { see }\end{array}$ & 0.5 & 5.3 & 28.9 & 46.1 & 19.2 & $3.78 \pm 0.83$ \\
\hline $\begin{array}{l}\text { 13. Assess the time to be examined and advised by } \\
\text { a doctor }\end{array}$ & 0.3 & 2.0 & 26.4 & 49.6 & 21.7 & $3.91 \pm 0.76$ \\
\hline 14. Assess waiting time for testing and screening & 1.0 & 8.0 & 29.9 & 42.9 & 18.2 & $3.69 \pm 0.89$ \\
\hline $\begin{array}{l}\text { 15. Assessing the waiting time for receiving results } \\
\text { of tests and screenings }\end{array}$ & 0.7 & 6.2 & 25.5 & 48.9 & 18.7 & $3.79 \pm 0.84$ \\
\hline $\begin{array}{l}\text { B. Transparency of information and } \\
\text { procedures for medical examination and } \\
\text { treatment (Average) }\end{array}$ & & & & & & $3.99 \pm 0.59$ \\
\hline
\end{tabular}

Note: 5=Strongly Agree, 4=Agree, 3=Neither Agree nor Disagree, 2=Disagree, 1=Strongly Disagree

Source: Primary data

Regarding the quality of the medical infrastructure and facilities, Table 4 shows that most of the respondents were satisfied with the conditions of the waiting room, the patient's privacy was kept confidentially when the investigation has taken, the CMI ensures the security to prevent theft, and creates the green campus surrounding the Institute. However, $54.1 \%$ of patients were not happy with the toilet and drinking water facility in OPD. 


\section{Table 4}

Distribution of responses from the respondents according to the quality of the medical infrastructure and facilities $(n=401)(\%)$

\begin{tabular}{|l|c|c|c|c|c|c|}
\hline \multicolumn{1}{|c|}{ Items of care } & \multicolumn{5}{|c|}{ Frequency (\%) } & Mean \pm SD \\
\hline $\begin{array}{l}\text { 16. Having clean, cool lounge / lounge in the } \\
\text { summer; Airtight and warm in winter }\end{array}$ & $\mathbf{1}$ & $\mathbf{2}$ & $\mathbf{3}$ & $\mathbf{4}$ & $\mathbf{5}$ & \\
\hline $\begin{array}{l}\text { 17. The waiting room has enough seats for the } \\
\text { patients and relatives and is in good use }\end{array}$ & 0.0 & 4.5 & 22.2 & 44.4 & 28.9 & $3.98 \pm 0.83$ \\
\hline $\begin{array}{l}\text { 18. The waiting room has full fan (air conditioner) } \\
\text { in regular operation }\end{array}$ & 0.0 & 1.2 & 25.2 & 44.4 & 29.2 & $4.01 \pm 0.77$ \\
$\begin{array}{l}\text { 19. The waiting room has facilities to help patients } \\
\text { feel comfortable such as television, pictures, } \\
\text { leaflets, drinking water ... }\end{array}$ & 0.0 & 2.0 & 23.7 & 50.9 & 23.4 & $3.96 \pm 0.74$ \\
\hline $\begin{array}{l}\text { 20. The CMI guarantees privacy for the patient's } \\
\text { medical examination, screening, procedures }\end{array}$ & 0.0 & 1.7 & 18.5 & 53.4 & 26.4 & $4.04 \pm 0.72$ \\
\hline $\begin{array}{l}\text { 21. The toilets are convenient, in good use, clean } \\
\text { 22. The environment campus surrounding the CMI } \\
\text { is green, clean and beautiful }\end{array}$ & 10.0 & 13.7 & 30.4 & 28.4 & 17.5 & $3.30 \pm 1.19$ \\
\hline $\begin{array}{l}\text { 23. Medical examination and treatment area ensures } \\
\text { security, order and prevents theft for people }\end{array}$ & 0.3 & 2.5 & 16.2 & 55.6 & 26.4 & $4.05 \pm 0.73$ \\
\hline $\begin{array}{l}\text { C. The quality of the medical infrastructure and } \\
\text { facilities (Average) }\end{array}$ & & & & & & $\mathbf{3 . 9 5} \pm \mathbf{0 . 6 5}$ \\
\hline
\end{tabular}

Note: 5=Strongly Agree, 4=Agree, 3=Neither Agree nor Disagree, 2=Disagree, 1=Strongly Disagree

Source: Primary data

Regarding the behavior, professional competence of medical and service staff, Table 5 shows that most of the respondents were satisfied with doctor and nurse attitude and communications with an average score of $4.20 \pm 0.60$ (out of 5). The patients felt satisfied with the doctor's explanation and the doctor's professional care. The patients were respected by the doctors and nurses, and service staff.

\section{Table 5}

Distribution of responses from the respondents according to the behavior, professional competence of medical and service staffs $(n=401)(\%)$

\begin{tabular}{|l|c|c|c|c|c|c|}
\hline \multicolumn{1}{|c|}{ Items of care } & \multicolumn{7}{|c|}{ Frequency (\%) } & Mean \pm SD \\
\hline & $\mathbf{1}$ & $\mathbf{2}$ & $\mathbf{3}$ & $\mathbf{4}$ & $\mathbf{5}$ & \\
\hline $\begin{array}{l}\text { 24. Doctors and nurses have the polite words, } \\
\text { attitudes and communication }\end{array}$ & 0.3 & 0.3 & 13.0 & 52.8 & 33.6 & $4.19 \pm 0.68$ \\
\hline $\begin{array}{l}\text { 25. Service staff (nurse, guard, accountant ...) } \\
\text { have the right words, attitudes and } \\
\text { communication }\end{array}$ & 0.0 & 1.5 & 14.2 & 54.1 & 30.2 & $4.13 \pm 0.70$ \\
\hline
\end{tabular}




\begin{tabular}{|l|c|c|c|c|c|c|}
\hline \multicolumn{1}{|c|}{ Items of care } & \multicolumn{5}{c|}{ Frequency (\%) } & Mean \pm SD \\
\hline $\begin{array}{l}\text { 26. Be respected by medical staff, treat them } \\
\text { fairly, care and help }\end{array}$ & 0.0 & 0.5 & 12.2 & 54.1 & 33.2 & $4.20 \pm 0.66$ \\
\hline $\begin{array}{l}\text { 27. Professional qualifications of doctors and } \\
\text { nurses meet expectations }\end{array}$ & 0.0 & 0.3 & 9.5 & 51.6 & 38.6 & $4.29 \pm 0.64$ \\
\hline $\begin{array}{l}\text { D. Behavior, professional competence of } \\
\text { medical and service staff }\end{array}$ & & & & & & $\mathbf{4 . 2 0} \pm \mathbf{0 . 6 0}$ \\
\hline
\end{tabular}

Note: 5=Strongly Agree, 4=Agree, 3=Neither Agree nor Disagree, 2=Disagree, 1=Strongly Disagree

Source: Primary data

Regarding the service delivery outcomes, Table 6 shows that the respondents expressed high satisfaction towards the outcomes of consultations, examinations and medication. The invoices and the outcomes were delivered in full and clear in detail. The respondents expressed trust in the quality of healthcare and satisfaction with the price of healthcare.

Regarding the one-item scale of overall patient satisfaction (Table 6), the average score of overall patient satisfaction level was 87.3 with a minimum of 50 to 100 . The distribution of overall satisfaction level was divided as follows: $73 \%$ of respondents selecting between 70 points to 100 points (good to excellent), 22\% selecting between 50 points to 70 points (average) and 5\% choosing less than 50 points (poor service). In this study, $94 \%$ of respondents answered "yes" to the question: "would you recommend this hospital to friends and family?"

\section{Table 6}

Distribution of responses from the respondents according to the outcome of service delivery $(\mathrm{n}=$ $401)(\%)$ and the one-item scale of patient satisfaction level (0-100)

\begin{tabular}{|l|c|c|c|c|c|c|}
\hline \multicolumn{1}{|c|}{ Items of care } & \multicolumn{5}{|c|}{ Frequency (\%) } & Mean \pm SD \\
\hline & $\mathbf{1}$ & $\mathbf{2}$ & $\mathbf{3}$ & $\mathbf{4}$ & 5 & \\
\hline $\begin{array}{l}\text { 28. The results of the examination met the } \\
\text { expectation of patients }\end{array}$ & 0.3 & 0.3 & 8.7 & 48.8 & 41.9 & $4.32 \pm 0.66$ \\
\hline $\begin{array}{l}\text { 29. Invoices, receipts, prescriptions and } \\
\text { medical examination results are provided } \\
\text { and explained in full, clear, transparent }\end{array}$ & 0.3 & 0.7 & 10.0 & 46.1 & 42.9 & $4.31 \pm 0.70$ \\
\hline $\begin{array}{l}\text { 30. Assess the level of trust in the quality of } \\
\text { health services }\end{array}$ & 0.3 & 0.3 & 8.0 & 50.3 & 41.1 & $4.32 \pm 0.65$ \\
\hline $\begin{array}{l}\text { 31. Assess the level of satisfaction with the } \\
\text { price of medical services }\end{array}$ & 0.0 & 0.0 & 10.0 & 49.4 & 40.6 & $4.31 \pm 0.64$ \\
\hline E. The outcome of service delivery & & & & & & $\mathbf{4 . 3 1} \pm \mathbf{0 . 6 1}$ \\
\hline $\begin{array}{l}\text { F. One-item scale of overall satisfaction } \\
\text { level (0 -100) }\end{array}$ & & & & & & $\mathbf{8 7 . 3} \pm \mathbf{1 1 . 7 2}$ \\
\hline
\end{tabular}

Note: 5=Strongly Agree, 4=Agree, 3=Neither Agree nor Disagree, 2=Disagree, 1=Strongly Disagree

Source: Primary data 


\subsection{The association of service quality and patient satisfaction}

The results of multiple regression analysis with the overall patient's satisfaction as a dependent variable presented in Table 7. These results showed that patients' satisfaction at the outpatient services was explained significantly by three components of healthcare services. The regression results confirmed the positive impact of "the transparency of information", "the competence of medical staff", and "the outcome of service delivery" on the patient satisfaction: $\beta$ $=3.10(\mathrm{p}<0.05) ; \beta=2.79(\mathrm{p}<0.05)$ and $\beta=6.05(\mathrm{p}<0.001)$ respectively. The regression model was found to be significant $(\mathrm{F}=40.22, \mathrm{p}<0.001)$, accounting for $33 \%$ of the variance in the data. In the table above, the variable "the outcome of service delivery" had the strongest relationship with the dependent variable, since its standardized beta is the highest $(0.312)$ following by the "transparency of the information". All of the variables have the variance inflation factor (VIF) lower than 4 indicating that there are no collinearity issues. The general rule of thumb is that VIF exceeding 4 warrants further investigation (Williams, 1994).

The second regression analysis with the outcome of service delivery as a dependent variable is presented in Table 8 . These results confirmed the positive impact of "transparency of information" $(\beta=0.12, p<0.05)$, and "the competence of medical and service staff" $(\beta=0.61, p$ $<0.05)$. In addition, the study found a significant impact on the quality of the medical infrastructure and facilities for the "outcome of service delivery" $(\beta=0.17, p<0.05)$.

\section{Table 7}

The association of Service Quality and patient Satisfaction $(n=401)$

\begin{tabular}{|c|c|c|c|c|}
\hline Service quality dimensions & $\begin{array}{c}\text { Unstandardized beta }(B) \\
\text { beta (SE B) }\end{array}$ & $\begin{array}{l}\text { Standardized } \\
\text { beta }(\beta)\end{array}$ & P-values & VIF \\
\hline Constant & $32.6095(4.1284)$ & & $<0.0001 * * *$ & \\
\hline $\begin{array}{l}\text { A: Accessibility of healthcare } \\
\text { service }\end{array}$ & $0.5329(1.2110)$ & 0.026 & 0.6601 & 2.14 \\
\hline B: Transparency of information & $3.1057(1.2757)$ & 0.158 & $0.0154 *$ & 2.50 \\
\hline $\begin{array}{l}\text { C: The quality of the medical } \\
\text { infrastructure and facilities }\end{array}$ & $0.5883(1.1617)$ & 0.032 & 0.6128 & 2.45 \\
\hline $\begin{array}{l}\text { D: Competence of medical and } \\
\text { service staff }\end{array}$ & $2.7861(1.3569)$ & 0.142 & $0.0407 *$ & 2.86 \\
\hline E: Service delivery outcome & $6.0516(1.2483)$ & 0.312 & $<0.0001 * * *$ & 2.48 \\
\hline
\end{tabular}

Adjusted R2 $=0.33 ; \mathrm{F}(5,395)=40.22 ; \mathrm{p}<0.001$

SE: Standard errors are reported in parentheses.

$*, * *, * * *$ indicates significance at the $90 \%, 95 \%$, and $99 \%$ level, respectively

VIF: Variance inflation factor

Source: The researcher's data analysis 


\section{Table 8}

The association of Service Quality and the outcome of service delivery $(n=401)$

\begin{tabular}{|l|c|c|c|c|}
\hline \multicolumn{1}{|c|}{ Service quality dimensions } & $\begin{array}{c}\text { Unstandardized beta } \\
(\mathbf{B}) \text { beta (SE B) }\end{array}$ & $\begin{array}{c}\text { Standardized } \\
\text { beta ( })\end{array}$ & P-values & VIF \\
\hline Constant & $0.94061(0.15933)$ & & $<0.0001$ & \\
\hline A: Accessibility of healthcare service & $-0.08653(0.04856)$ & -0.083 & 0.07 & 2.12 \\
\hline B: Transparency of information & $0.12010(0.05100)$ & 0.12 & $0.02^{*}$ & 2.47 \\
\hline $\begin{array}{l}\text { C: The quality of the medical infrastructure } \\
\text { and facilities }\end{array}$ & $0.16883(0.04599)$ & 0.18 & $0.000275^{* * *}$ & 2.36 \\
\hline D: Competence of medical and service staff & $0.61458(0.04505)$ & 0.60 & $<0.0001^{* * *}$ & 1.95 \\
\hline
\end{tabular}

Adjusted R2 = 0.593; F $(4,396)=146.7 ; \mathrm{p}<0.001$

Sig.: Significance test of Multivariable Linear regression

Standard errors are reported in parentheses

$*, * *, * * *$ indicates significance at the $90 \%, 95 \%$, and $99 \%$ level, respectively

Source: The researcher's data analysis

\subsection{Differences in patient satisfaction according to the socio-demographic characteristics of patients}

The multivariable logistic regression was applied to examine the patient satisfaction according to different socio-demographic characteristics of patients. The "outcomes of service delivery" were categorized to "dissatisfaction" for the responses that were rated for 1,2,3 according to Likert scale and for 4 and 5 for the "satisfaction". Table 9 showed that there were no significant differences between patient satisfaction between gender, age groups, and having insurance or not, or the distance from home to hospital.

\section{Table 9}

Comparison of mean satisfaction scores according to the socio-demographic characteristics of patients $(\mathrm{n}=401)$

\begin{tabular}{|c|c|c|c|c|c|}
\hline \multicolumn{2}{|c|}{ Patient's characteristics } & $\begin{array}{c}\text { Dissatisfaction } \\
n(\%)\end{array}$ & $\begin{array}{c}\text { Satisfaction } \\
\mathbf{n}(\%)\end{array}$ & OR (95\% CIs) & p- value \\
\hline \multirow{2}{*}{ Response type } & Patients & $175(48.9)$ & $183(51.1)$ & 1 & \\
\hline & Relative & $17(53.1)$ & $15(46.9)$ & $1.18(0.57-2.44)$ & 0.646 \\
\hline \multirow{2}{*}{ Gender } & Male & $8(34.8)$ & $81(38.9)$ & 1 & \\
\hline & Female & $15(65.2)$ & $123(61.1)$ & $0.55(0.15-1.76)$ & 0.335 \\
\hline \multirow{3}{*}{$\begin{array}{l}\text { Age groups } \\
\text { (years) }\end{array}$} & $<18$ & 0 & $8(2.1)$ & 1 & \\
\hline & $18-59$ & $14(60.9)$ & $200(52.9)$ & $0.91(0.27-2.93)$ & 0.874 \\
\hline & $\geq 60$ & $9(39.1)$ & $170(45.0)$ & $1.61(0.37-6.95)$ & 0.522 \\
\hline \multirow{2}{*}{ Insurance } & Yes & $15(65.2)$ & $168(44.4)$ & 1 & \\
\hline & No & $8(34.8)$ & $210(55.6)$ & $2.53(0.82-8.48)$ & 0.115 \\
\hline \multirow{2}{*}{$\begin{array}{c}\text { Distance from home } \\
\text { to hospital }\end{array}$} & $<200$ & $15(65.2)$ & $248(65.5)$ & 1 & \\
\hline & $\geq 200$ & $8(34.8)$ & $130(34.4)$ & $1.02(0.40-2.41)$ & 0.969 \\
\hline
\end{tabular}

Note: $95 \%$ CIs: $95 \%$ confidence intervals

OR: Odds ratios of demographic characteristics of respondents

Source: The researcher's data analysis 


\section{Discussion}

The analysis reveals that patients are satisfied with the outpatient facilities provided at the Heart Institute of Ho Chi Minh City in Vietnam. The degree of patient satisfaction for the service quality was at an acceptable level (around the score of four) ranging from the accessibility of healthcare services $(4.12 \pm 0.58)$, the transparency of information and procedures for medical examination and treatment $(3.99 \pm 0.59)$, the quality of the medical infrastructure and facilities $(3.95 \pm 0.65)$, the behavior, professional competence of medical and service staffs $(4.20 \pm 0.60)$, the outcome of service delivery $(4.31 \pm 0.61)$. Most of the patients were not happy with the booking services via phone, and website and online services, the long waiting times to get registered, to see the doctors, to do the investigations and receive the results, and also the condition of toilet and drinking water facility in OPD. These issues have also been encountered from studies in developing countries (Kulkarni, 2018; Singh \& Kumar, 2015).

These findings are in line with the reports in the literature from Vietnam which have shown that the majority of patients ( $80 \%$ or more) expressed satisfaction with their care, with a few responding negatively to any given items (Nguyen \& Mai, 2014). However, this positive appreciation might have resulted from patients being unwilling to express dissatisfaction for fear of displeasing staff and experiencing even worse service in the future (Batchelor et al., 1994). Further study on this topic may be desirable to confirm the results.

In addition, this study focused on investigating the relationship between service quality and patient satisfaction at the Heart Institute of Ho Chi Minh City. The findings indicated that three service quality dimensions, "the transparency of information", "the competence of medical staff" and "the quality of the medical infrastructure and facilities" significantly determined the patient satisfaction and the outcome of service delivery. The results of our research, in line with the findings from previous studies, confirmed the impact of "competence of professional staff" and "facilities and tangibles" on Vietnamese patient satisfaction (Nguyen \& Mai, 2014). The importance of tangible elements such as booking facilities, electronic medical equipment and infrastructure influence patient satisfaction. Our study also provides empirical evidence for the strong impact of competence of medical staff and doctors and the transparency of information to improve patient satisfaction. Of the socio-demographic assessed, the results of our study could not demonstrate the noted differences in satisfaction be-tween age groups, gender and having insurance or not and distance from home to hospital.

\section{Implications}

The findings from this study contribute to a better understanding of the quality of outpatient services provided by the Heart Institute of Ho Chi Minh City and their impact on the level of patient satisfaction with cardiovascular diseases.

Several managerial implications are offered to the administrators at the Heart Institute of Ho Chi Minh City to enhance patient satisfaction. It is necessary for the managers to pay attention to improve the elements of facilities and services, especially the bed, water drinking and toilet conditions. The CMI should consider implementing electronic booking to reduce the waiting time for registration and the consultation. It is also very important to continue to promote an attitude of medical staff and doctors towards patients, as well as provide training to medical staff and physicians to enhance the speed of the process but still ensures the quality of communication, skills/specialization and transparent culture.

Recommendations to the Institue: 
1. Improve the technical quality of care to book an appointment, make more investment to the system infrastructure to reduce the waiting times;

2. The physical environment should be improved to cleanliness;

3. Enhance the inter-professional and inter-departmental collaborations. Accessibility/ convenience should be arranged to increase more medical staff to minimize waiting times;

4. Continue to improve the medical and services staff's manner, in which providers interact personally with patients and respond promptly to patient's questions and requests.

\section{Limitations of the study and future research directions}

The major limitations of the study are the fact that it was cross-sectional and conducted at a single center. A study conducted in other parts of Vietnam and across time intervals could be further extended. Despite the limitations, the findings have presented the patient view regarding the quality of healthcare services from the top of the national centre that is specialized in treating cardiovascular diseases and remains as the model for medical practice in the nation. Hence, the findings of this study can be considered as representative of the patient satisfaction toward the cardiology outpatient services in Vietnam and can help the managers enhance the patient satisfaction level by concentrating on the factors identified as determinants of satisfaction in patients.

\section{Conclusion}

Overall most of the patients positively evaluated the transparency of information regarding disease conditions and the competence of medical staff at the Heart Institute of Ho Chi Minh City but there are still some aspects of healthcare services that need to improve such as the medical infrastructure, electronic facilities to reduce the waiting times and enhance more transparent information to patients. This study provides empirical evidence to help healthcare managers make policies and develop action plan programs to improve the quality of service for patients with cardiovascular diseases.

\section{References}

Al-Abri, R., \& Al-Balushi, A. (2014). Patient satisfaction survey as a tool towards quality improvement. Oman Medical Journal, 29(1), 3-7. doi:10.5001/omj.2014.02

Batchelor, C., Owens, D. J., Read, M., \& Bloor, M. (1994). Patient satisfaction studies: Methodology, management and consumer evaluation. International Journal of Health Care Quality Assurance, 7(7), 22-30. doi:10.1108/09526869410074720

Bird, V. J., Giacco, D., Nicaise, P., Pfennig, A., Lasalvia, A., Welbel, M., \& Priebe, S. (2018). Inpatient treatment in functional and sectorised care: Patient satisfaction and length of stay. British Journal of Psychiatry, 212(2), 81-87. doi:10.1192/bjp.2017.20

Cronin, J. J., \& Taylor, S. A. (1992). Measuring service quality: A reexamination and extension. Journal of Marketing, 56, 55-68. doi:10.1177/002224299205600304

Gogoi, S., \& Choudhury, B. (2015). Patient satisfaction in a multispeciality hospital of North East India: A cross sectional study. International Journal of Pharma Research and Health Sciences, 3(3), 700-707.

Ho, N. B. (2015). The inpatient satifaction for the quality of medical services of hospitals in Long Xuyen City, Vietnam. An Giang University Medical Journal, 6(2), 111-119. 
Hoang, M. V., Dao, H. L., Wall, S., Nguyen, C. T. K., \& Byass, P. (2006). Cardiovascular disease mortality and its association with socioeconomic status: Findings from a population-based cohort study in rural Vietnam, 1999-2003. Preventing Chronic Disease, 3(3), 1-11.

Kulkarni, S. K. (2018). A study of patient satisfaction level in Out Patient Department (OPD) in a tertiary care hospital in Maharashtra. Journal of Dental and Medical Sciences, 17(3), 31-39. doi:10.9790/0853-1703073139

Mitropoulos, P., Vasileiou, K., \& Mitropoulos, I. (2018). Understanding quality and satisfaction in public hospital services: A nationwide inpatient survey in Greece. Journal of Retailing and Consumer Services, 40, 270-275. doi:10.1016/j.jretconser.2017.03.004

Nguyen, C. T., \& Mai, N. T. T. (2014). Service quality and its impact on patient satisfaction: An investigation in Vietnamese public hospitals. Journal of Emerging Economies and Islamic Research, 2(August), 1-13.

Olusina, A. K., Ohaeri, J. U., \& Olatawura, M. O. (2002). Patients and staff satisfaction with the quality of in-patient psychiatric care in a Nigerian general hospital. Social Psychiatry and Psychiatric Epidemiology, 37(6), 283-288. doi:10.1007/s00127-002-0548-5

Parasuraman, A., Zeithaml, V., \& Berry, L. (1988). SERVQUAL: A multiple-item scale for measuring consumer perceptions of service quality. Journal of Retailing, 64(1), 12-40.

Pham, D. T., Le, H. T. T., Bui, H. T. T., \& Ly, T. T. N. (2011). Nghiên cúu sụ hài lòng của ngưòi bệnh ngoại trú về dịch vụ khám, chũa bệnh tại khoa khám bệnh của ba bệnh viện hạng III [Study on the satisfaction of outpatients on medical examination and treatment services at the medical department of three hospital class III]. Retrieved Octorber 7, 2020, from http://www.yhth.vn/nghien-cuu-su-hai-long-cua-nguoi-benh-ngoai-tru-ve-dich-vu-khamchua-benh-tai-khoa-kham-benh-cua-ba-benh-vien-hang-iii_t2178.aspx

Sachdeva, S., \& Kaur, H. (2018). A study to assess the patient satisfaction regarding treatment and care in emergency department of New Delhi hospital, India. Nursing \& Care Open Access Journal, 5(6), 357-360. doi:10.15406/ncoaj.2018.05.00173

Singh, D. S., \& Kumar, D. V. (2015). Satisfaction level of patients in outpatient department at a general hospital, Haryana. Inernational Journal of Management (IJM), 6(1), 670-678.

Sitzia, J., \& Wood, N. (1997). Patient satisfaction: A review of issues and concepts. Social Science and Medicine, 45(12), 1829-1843. doi:10.1016/S0277-9536(97)00128-7

Stefanovska, V. V., \& Petkovska, M. S. (2014). Patient satisfaction in outpatient healthcare services at secondary level vs. tertiary level. Srpski Arhiv Za Celokupno Lekarstvo, 142(9/10), 579-585. doi:10.2298/SARH1410579V

Tran, B. X., \& Nguyen, N. P. T. (2012). Patient satisfaction with HIV/AIDS care and treatment in the decentralization of services delivery in Vietnam. PLoS ONE, 7(10), 3-7. doi:10.1371/journal.pone.0046680

Williams, B. (1994). Patient satisfaction: A valid concept? Social Science and Medicine, 38(4), 509-516. doi:10.1016/0277-9536(94)90247-X

World Health Organization (WHO). (2016). Definition of cardiovascular diseases. Retrieved Octorber 6, 2020, from https://www.euro.who.int/en/health-topics/noncommunicablediseases/cardiovascular-diseases/cardiovascular-diseases2/definition-of-cardiovasculardiseases. 